\title{
Neonatal health of parents and cognitive development of children
}

Kreiner, Claus Thustrup; Sievertsen, Hans Henrik

Published in:

Journal of Health Economics

DOI:

10.1016/j.jhealeco.2019.102247

Publication date:

2020

Document version

Publisher's PDF, also known as Version of record

Document license:

CC BY-NC-ND

Citation for published version (APA):

Kreiner, C. T., \& Sievertsen, H. H. (2020). Neonatal health of parents and cognitive development of children. Journal of Health Economics, 69, [102247]. https://doi.org/10.1016/j.jhealeco.2019.102247 


\title{
Neonatal health of parents and cognitive development of children*
}

\author{
Claus Thustrup Kreiner ${ }^{\mathrm{a}}$, Hans Henrik Sievertsen ${ }^{\mathrm{b}}$ \\ a University of Copenhagen, CEBI and CEPR, Denmark \\ b University of Bristol and VIVE, United Kingdom
}

\section{A R T I C L E I N F O}

\section{Article history:}

Received 19 November 2018

Received in revised form 13 August 2019

Accepted 9 October 2019

Available online 30 November 2019

\section{JEL classification:}

I12

J13

$\mathrm{J} 24$

\section{Keywords:}

Neonatal health

Human capital formation

Intergenerational dependency

\begin{abstract}
A B S T R A C T
It is well-established that neonatal health is a strong predictor of socioeconomic outcomes later in life, but does neonatal health also predict key outcomes of the next generation? This paper documents a surprisingly strong relationship between birth weight of parents and school test scores of their children. The association between maternal birth weight and child test scores corresponds to 50-80 percent of the association between the child's own birth weight and test scores across various empirical specifications, for example including grandmother fixed effects that isolate within-family differences between mothers. Paternal and maternal birth weights are equally important in predicting child test scores. Our intergenerational results suggest that inequality in neonatal health is important for inequality in key outcomes of the next generation.
\end{abstract}

(C) 2019 The Authors. Published by Elsevier B.V. This is an open access article under the CC BY-NC-ND license (http://creativecommons.org/licenses/by-nc-nd/4.0/).

\section{Introduction}

Today, it is a stylized fact that inequality in birth endowments is related to inequality in key socioeconomic outcomes later in life (Currie, 2011). For example, many studies have documented a relationship between birth weight and measures of cognitive development (Almond and Currie, 2010), and this relationship exists within siblings, thereby holding family background fixed

\footnotetext{
* *We thank Douglas Almond, Heather Royer and numerous seminar participants for helpful comments and discussions. We are also thankful for improvements suggested by two anonymous referees. We are grateful to the Danish Ministry for Education for providing access to data on school grades. Sievertsen acknowledges support from The Danish Council for Strategic Research, Grant DSF-09-070295. The activities of Center for Economic Behavior and Inequality (CEBI) are funded by the Danish National Research Foundation.

E-mail addresses: ctk@econ.ku.dk (C.T. Kreiner), h.h.sievertsen@bristol.ac.uk (H.H. Sievertsen).
}

(Currie and Moretti, 2007; Black et al., 2007), and it exists when measuring performance of children early in school (Figlio et al., 2014).

We ask whether neonatal health of one generation (birth weights of parents) is important for the cognitive development of the next generation (early school performance of children)? The intergenerational literature has established a strong correlation across generations for a huge set of socioeconomic outcomes (Solon, 1999; Black and Devereux, 2011; Chetty et al., 2017; Boserup et al., 2018; Landersø et al., 2017), including birth weight (Currie and Moretti, 2007; Royer, 2009). As a result, it is natural to expect that differences in birth weight within a generation are associated with differences in cognitive development of the next generation. Based on estimates of the intergenerational correlation in birth weight and the correlation between birth weight and school test scores, we may form a conjecture about the importance of parental birth weight for child test scores. Estimates for the US (Currie and 
Moretti, 2007) and for Denmark (this study) show that a one percent higher birth weight of the mother is associated with a 0.2 percent higher birth weight of the child. Estimates for the US (Figlio et al., 2014) and for Denmark (this study) show that a one percent higher birth weight of the child is associated with higher test scores in elementary school of 0.3 percent of a standard deviation (SD percent). From these (partial) estimates, we may expect that a one percent higher birth weight of the mother is associated with a 0.05 SD percent higher test score of the child (i.e. $0.2 * 0.3 \approx 0.05){ }^{1}$

This conjecture would be correct if neonatal health of children is a 'sufficient statistic' incorporating maternal neonatal health. We find that maternal neonatal health plays a much larger role. A one percent higher maternal birth weight is associated with a 0.25 SD percent higher child test score. This is around five times larger than the conjecture, and it is 80 percent of the association between the child's own birth weight and test score. When running a multivariate regression that includes birth weights of both the child and the mother, we find a coefficient on the mother equal to $0.2 \mathrm{SD}$ percent and, again, close to 80 percent of the child coefficient. We also provide nonparametric evidence showing a strong association between maternal birth weight and child test scores, conditional on the birth weight of the child, throughout the child birth weight distribution.

A key question is whether the estimated relationship between maternal birth weight and child test scores reflects a causal effect or a selection effect. A selection effect can occur because family background of the mothers affects both maternal birth weight and child school performance. Currie and Moretti (2007) and Figlio et al. (2014) show that the aforementioned relationships between birth weights of two generations and between an individual's own birth weight and school test scores also exist when looking at the variation within siblings. Using a similar strategy, we keep family background fixed by estimating the effect of differences in birth weight between sisters on the test scores of their offspring. When repeating the univariate and multivariate regressions with fixed effects, we find in both cases that a one percent higher maternal birth weight is associated with a 0.1-0.15 SD percent higher child test score, corresponding to approximately 50 percent of the coefficient on the child's own birth weight. These results point to the existence of a significant causal effect of maternal birth weight on child test scores.

The significant coefficient on the birth weight of the mother, when including the birth weight of the child in the fixed effect regressions, may reflect a causal effect of maternal birth weight conditional on child birth weight, but this is not necessarily the case. We show theoretically that an alternative explanation can be that variation in child birth weight related to maternal birth weight is more impor-

\footnotetext{
1 We are not aware of other countries where there exist estimates of both the intergenerational correlation in birth weight and the correlation between birth weight and early school performance of children. We obtain the same conjecture based on estimates for Norway reported in Black et al. (2007) if we use their estimates of the correlation between birth weight and IQ measured for males at age 18 .
}

tant for child cognitive development than the variation in child birth weight unrelated to maternal birth weight. In this case, the causal effect of maternal birth weight can run entirely through child birth weight. However, independent of the causal mechanism at play, the conclusion is that inequalities in birth endowments of mothers have significant consequences for individuals in the next generation.

For a smaller subsample, we also have information about the birth weight of the father. Non-parametric evidence for this subsample reveals that child test scores are also strongly associated with paternal birth weight, conditional on the birth weight of the child, throughout the child birth weight distribution. When repeating the basic regression analysis with birth weights of both mothers and fathers, we find that the two birth weight coefficients are of nearly the same size across all specifications. For example, when running multivariate regressions with birth weights of both children and parents, we find a coefficient of around 0.2 SD percent for both parents and close to 80 percent of the child coefficient. Thus, maternal and paternal birth endowments are strong and equally good predictors of child school performance.

We provide three sensitivity analyses to address potential concerns about model misspecification, sample selection bias and external validity. First, we show that our results are robust to model specification. For example, the results become similar if we, instead of using a standard specification with the logarithm of birth weight, use a low birth weight indicator, defined conventionally as a birth weight below $2500 \mathrm{~g}$ (Chaikind and Corman, 1991). Second, to address concerns about sample selection, we redo the basic analysis on another sample of births and reach the same conclusions. This sample is smaller and has only survey information on maternal birth weight, but the survey population is representative of all births, unlike the administrative data where mothers on average are younger because of lack of birth weight information for older mothers. Third, to address concerns about external validity, we replicate recent evidence for the US by Figlio et al. (2014) on the relationship between the birth weight of an individual and school test performance in elementary school. This suggests that our main results on the relationship between neonatal health of parents and cognitive development of children are also relevant for the US and probably other countries. The similar results for Denmark and the US are also interesting because of the very different institutional settings, with Denmark having publicly provided universal health care (including pre-natal and post-natal care) and a tax-financed school system, with a very limited role of privately financed supplementary spending on health care and education.

The results in this paper complement recent findings demonstrating a long run impact of neonatal health on individual outcomes (Bharadwaj et al., 2018, 2019). Several studies show that endowments at birth are affected by external factors such as nutritional shocks, health shocks, tobacco policies, stress and environmental factors (Almond and Currie, 2011; Almond and Mazumder, 2011; Currie and Schwandt, 2013, 2016; Harris et al., 2015; Carlson, 2015; Black et al., 2016; Persson and Rossin-Slater, 2018). Our finding that inequalities in endowments at birth persist 
into the next generation indicates that external factors, as well as health innovations and policies, affecting birth endowments can have significant effects on the next generation.

The rest of the paper proceeds as follows: Section 2 describes our data. Section 3 presents the main empirical results on the relationship between parental neonatal health and child school performance. Section 4 assesses the generalizability of the findings. Section 5 provides concluding remarks.

\section{Data}

\subsection{Sources}

The information on each individual is based on three data sources linked together through a unique personal identifier. The first data source is The Medical Birth Registry, which contains information on all births in Denmark for the period 1973-2014. The registry includes information on birth outcomes (birth weight, child height, gestational age), date of birth, parity, gender and birth place, as well as personal identifiers for the child, the mother and the father. Information on births in hospitals is based on data from the hospital registry while information on home births comes from reports by the midwife.

The second data source is provided by the Danish Ministry of Education and contains information on test results for the Danish National Tests in public schools. The test program was introduced in 2010. All children in compulsory schooling have to take a reading test in grades 2,4 , 6 , and 8 , a math test in grads 3 and 6 , and a test in each of the subjects English, Geography, Physics/Chemistry and Biology during grades $7-8$. Three cognitive domains are tested simultaneously in each test. The math tests assess numbers and algebra, geometry and applied mathematics. The reading tests assess language comprehension, decoding and reading comprehension. The tests are IT-based and teachers are not involved in test design or in assessment of the test results. The purpose of the national test program is to provide teachers with an instrument for assessment and feedback. The program and tests are described in greater detail in Beuchert and Nandrup (2018), which also shows that the test results are highly predictive of the exam grades of the students at the end of compulsory schooling. Data from the National Tests has been used for research before by Andersen et al. (2016) and Sievertsen et al. (2016). Our dataset contains all tests for the period 2010-2016, giving more than three million test results. The data contains information on the raw test results, the test date and time, a school identifier, the test subject and the child's grade.

The third data source is administrative data from Statistics Denmark. This data contains information about income and education (degree completed). The income measures of Statistics Denmark are based on third-party reports from employers to the tax authorities who use it for tax assessment and selection for audit, and the data is therefore of high quality (Kleven et al., 2011).

In Denmark, each individual is given a unique personal identifier at birth (the so-called CPR number) and this is registered together with the personal identifiers of the par- ents. We use the personal identifier from the CPR-Registry to obtain an exact link across the three datasets and across generations: for each child we first merge information from the birth registry with information on test outcomes and background characteristics using the personal identifier. We then merge the child data with data on parental background (income, education, etc.) using the unique identifier from the CPR-Registry.

To complement the study based on administrative registers, we further use data from the Danish National Birth Cohort (DNBC), which is a nationwide survey of almost 100,000 pregnant women in Denmark between 1997 and 2004, in which the mother was interviewed during pregnancy and at the beginning of the child's life. The survey contains self-reported information about the birth weight of the mothers, which enables us to assess our findings on a smaller, but more representative, sample of mothers and children.

\subsection{Sample selection}

The point of departure for our sample selection is the 927,805 children born in Denmark from 1995 to 2007. The tests are only mandatory in public schools, which enables us to match 740,769 of the children to test results in primary school. ${ }^{2}$ Our sample is reduced to 226,304 (31 percent of the matched child birth weight and child test score data) when we merge the child records with the information on maternal birth weight. This reduction in sample size is caused by the fact that the mother has to be born in 1973 or later in order to be included in the Medical Birth Registry. The two sources of sample selection could lead to non-representative samples. However, as Fig. 1 shows, the samples have remarkably similar birth weight distributions (Panel A) and test score distributions (Panel B). In addition, we replicate our main results on the smaller, but more representative DNBC survey sample in a robustness analysis in Section 4.

\subsection{Variable definitions}

\subsubsection{Birth weight}

Data accuracy in the Medical Birth Registry is very high as the information is provided directly from hospital records for births in hospitals, comprising about 99 percent of all births, and by midwives for all home births. Moreover, the birth outcomes (including birth weight) are recorded by health professionals (i.e. not self-reported). However, from 1973 to 1978 , birth weight was recorded in 500-g intervals, and from 1979 to 1989 birth weight was recorded in 10 -g intervals, and as of 1990 , birth weight is recorded in 1-g units. For the births between 1973 and 1989, we use the midpoints of the bins. This may result in attenuation bias and work against finding a relationship. Therefore, we

\footnotetext{
${ }^{2}$ In 2007, public schools accounted for 81.4 percent of all students, boarding schools (Danish: "Efterskoler") account for 3.6 percent, private schools (Danish: "Friskoler og private grundskoler") for 12.9 percent and the remaining two percent are in schools for children with special needs and other schools (Danish: specialskoler, behandlingshjem, kommunale ungdomsskoler, etc.).
} 
a Birth weight distribution

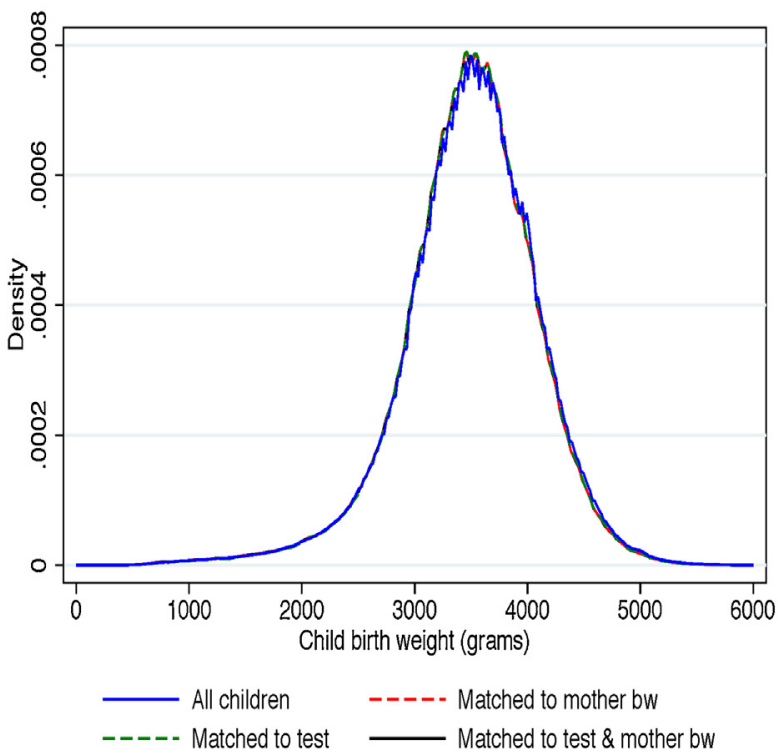

b Test score distribution

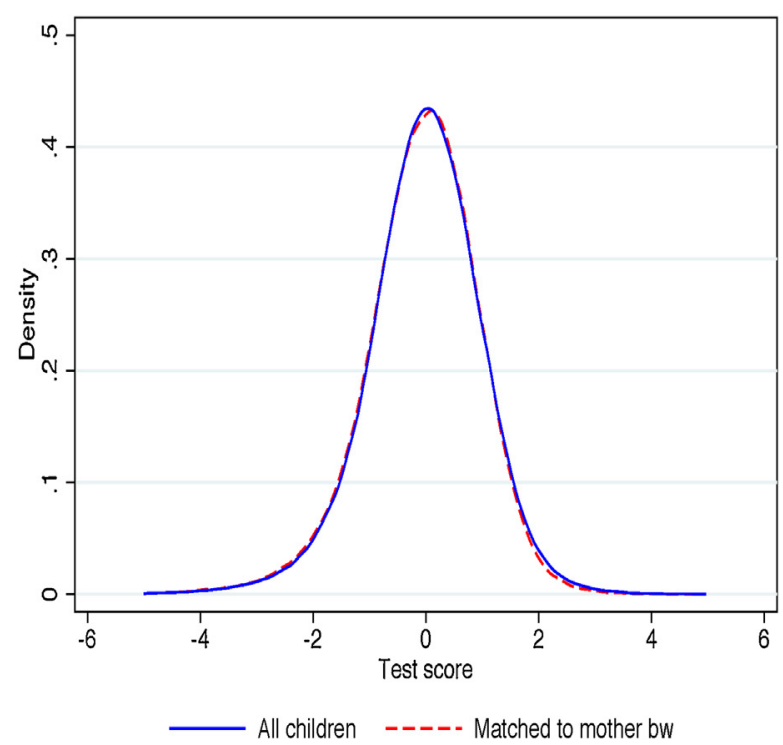

Fig. 1. Birth weight and test score distributions for each step of the sample selection. Notes: Based on all children born in Denmark from 1995 to 2007. Test scores are standardized to have mean zero and unit standard deviation by test year, test subject and grade. The densities are estimated using an Epanechnikov kernel with the "optimal” bandwidth.

assess the robustness of our results by using an indicator specification, where we estimate the impact of a low birth weight, defined as a birth weight below $2500 \mathrm{~g}$. Furthermore, we replicate our main findings using the continuous, self-reported, measure of maternal birth weight in the survey data from the DNBC.

\subsubsection{Test scores and child variables}

We use all tests from all subjects (Math, Reading, English, Geography, Biology and Physics) across all grades $(2,3,4,6$ and 8$)$ in the empirical analysis. We follow previous studies by standardizing the test scores to have a mean of zero and a unit standard deviation for groups of observations having same test year, same test subject and same grade. $^{3}$ This implies that each test score measures the deviation from the mean score of all children taking the test in the same grade and the same subject in the same year, measured in standard deviations. For each test we also create variables for the test grade (indicators), test year (indicators) and the subject of the test (indicators). For each child we create variables on year of birth (indicators), month of birth (indicators), gender (indicator), birth order (indicators), number of siblings (indicators) and an indicator for whether the child is a singleton.

\footnotetext{
${ }^{3}$ In Appendix Table A.2, we redo the main analysis for each of the six subjects separately. The associations between birth weights and test scores are very similar across subjects. In that table we also show results from a specification where test scores are standardized by calendar year, subject, grade (as in the main analysis) as well as birth cohort. The inclusion of birth cohort in the standardization has negligible effects on the results.
}

\subsubsection{Parental characteristics}

Each child record is matched to information on parental disposable income (gross income minus taxes plus transfers), a self-employment indicator, highest completed education and age at child birth. We measure the parental characteristics in the calendar year, two years prior to child birth. The advantage of this approach is that the variables are measured before the neonatal health of the child is observed. However, as these variables are measured at a relatively early stage of the parents' careers, they may not be perfectly representative of the parents' human and economic capital. Therefore, we also show results where parental variables are measured in the calendar year, 5 years after child birth. While this approach more accurately captures parental resources, it is also likely to be endogenously affected by the child's neonatal health. Throughout the analysis, we include mother and father variables separately.

\subsection{Summary statistics}

Table 1 provides variable means and standard deviations as well as the median, the first quartile and the third quartile for a number of key variables. The average birth weight is $3487 \mathrm{~g}$ and 5 percent of the children have a low birth weight (birth weight below $2500 \mathrm{~g}$ ). The mean is slightly higher than the $3342 \mathrm{~g}$ (for singletons) in the data from Florida used by Figlio et al. (2014), where 5.9 percent of the singletons have a low birth weight.

The mothers have a somewhat lower mean birth weight than their children who, on average, are born 27 years later. The difference in mean birth weight is primarily driven by the right tail, as a smaller share of mothers have a birth 
Table 1

Summary statistics.

\begin{tabular}{|c|c|c|c|c|c|}
\hline & Mean & SD & P25 & P50 & P75 \\
\hline \multicolumn{6}{|l|}{ A. Child variables } \\
\hline Birth weight, g & 3487 & 588 & 3160 & 3500 & 3860 \\
\hline Birth weight $<2500$ g & 0.05 & 0.21 & 0.00 & 0.00 & 0.00 \\
\hline $2500 \leq$ Birth weight $<3000 \mathrm{~g}$ & 0.11 & 0.32 & 0.00 & 0.00 & 0.00 \\
\hline $3000 \leq$ Birth weight $<3500 \mathrm{~g}$ & 0.32 & 0.46 & 0.00 & 0.00 & 1.00 \\
\hline Birth weight $\geq 3500 \mathrm{~g}$ & 0.52 & 0.50 & 0.00 & 1.00 & 1.00 \\
\hline Female & 0.49 & 0.50 & 0.00 & 0.00 & 1.00 \\
\hline Singleton & 0.97 & 0.18 & 1.00 & 1.00 & 1.00 \\
\hline Number of siblings & 1.53 & 0.70 & 1.00 & 1.00 & 2.00 \\
\hline Number of tests & 3.96 & 2.58 & 2.00 & 3.00 & 6.00 \\
\hline \multicolumn{6}{|l|}{ B. Mother variables } \\
\hline Birth weight, g & 3295 & 539 & 2905 & 3250 & 3750 \\
\hline Birth weight $<2500$ g & 0.06 & 0.24 & 0.00 & 0.00 & 0.00 \\
\hline $2500 \leq$ Birth weight $<3000 \mathrm{~g}$ & 0.20 & 0.40 & 0.00 & 0.00 & 0.00 \\
\hline $3000 \leq$ Birth weight $<3500 \mathrm{~g}$ & 0.40 & 0.49 & 0.00 & 0.00 & 1.00 \\
\hline Birth weight $\geq 3500 \mathrm{~g}$ & 0.35 & 0.48 & 0.00 & 0.00 & 1.00 \\
\hline Age at child birth & 26.81 & 3.56 & 24.00 & 27.00 & 29.00 \\
\hline Years of schooling & 13.31 & 2.24 & 11.00 & 13.00 & 14.25 \\
\hline Annual net income (thousand EUR) & 17.18 & 8.40 & 12.19 & 17.43 & 21.70 \\
\hline \multicolumn{6}{|l|}{ C. Father variables } \\
\hline Age at child birth & 29.85 & 4.63 & 27.00 & 30.00 & 33.00 \\
\hline Years of schooling & 13.51 & 2.29 & 11.00 & 14.00 & 14.50 \\
\hline Annual net income (thousand EUR) & 22.21 & 12.32 & 16.49 & 22.35 & 27.25 \\
\hline Individuals & & & 226,304 & & \\
\hline Observations & & & 895,587 & & \\
\hline
\end{tabular}

Notes: The sample consists of all children born 1995-2007 matched to test results, child birth weight and mother birth weight. Only observations with non-missing parental date of birth and birth order are included. Parental characteristics are measured in the calendar year, two years prior to child birth. Birth weight is measured in 500-g intervals from 1973 to 1978 and in ten-gram intervals from 1979 to 1989. For individuals (mothers) born in these years we use the midpoint of the bin. Parental incomes are adjusted to the 2015 price level using the consumer price index. In the few cases where parental variables have missing values we assign the observation a random value drawn from the distribution of non-missing observations. We do not report the birth weight of the father, as this information only exists for a subsample.

weight above $3500 \mathrm{~g}$. Both parents have completed on average about 13 years of schooling.

\section{Relationship between neonatal health of parents and school performance of children}

This section presents the main empirical results. First, we study the relationship between maternal birth weight and child test score in the full sample. Second, we consider the same relationship for the subsample of mothers having sisters in the sample, enabling us to study how the within family variation in birth weights of mothers relates to differences in the test scores of their children. Third, we discuss two potential mechanisms underlying the association between maternal birth weight and child test scores. Finally, we redo the first part of the analysis for a subsample where we also have information about the birth weight of the father.

\subsection{Maternal birth weight and child test scores}

Previous studies have looked at the association between birth weight and school test scores of an individual, as well as the intergenerational correlation in birth weight between the child and the mother. We first replicate previous findings using our data. The first row in Table 2 reports the result from estimating a simple linear relationship between the (normalized) test score and the natural logarithm of birth weight in grams for all individuals in our sample. We pool test scores across all grades and, to be conservative, we cluster standard errors at the grandmother level. ${ }^{4}$ The OLS estimate is 0.28 and is precisely estimated with a 95 percent confidence interval of $(0.26,0.30)$. The point estimate means that a one percent increase in birth weight is associated with a 0.3 SD percent increase in test scores. This is in line with the recent evidence for the US in Figlio et al. (2014); column 1 of panels A and B in their Table 2 reports a coefficient of 0.29 for both singletons and twins. The second row in Table 2 reports the result from regressing the logarithm of the child's birth weight on the logarithm of the mother's birth weight. The OLS estimate is 0.18 , implying that a one percent increase in the birth weight of the mother is associated with a 0.18 percent increase in the birth weight of the child. This estimate is very close to the findings for the US in Currie and Moretti (2007); column 1, row 3 of their Table 2 reports a coefficient of $0.20 .^{5}$

\footnotetext{
${ }^{4}$ To be precise, we cluster standard errors at the grandmother level on the mother side. This is a natural choice later in the analysis where we study within-sister variation of mothers using sibling fixed effect models. For consistency, we also cluster standard errors at the grandmother level in this part of the analysis. Standard errors are slightly smaller if we cluster standard errors at the mother level or at the child level.

${ }^{5}$ Currie and Moretti (2007) survey previous studies of the intergenerational correlation in birth weight. Our results are also in the same ballpark as Royer (2009) who estimates, for a female twin sample, that a 1-g higher birth weight of the mother is associated with a $0.18 \mathrm{~g}$ higher birth weight of the child (Table 3, panel B, column 1). We find an association of 0.21 (see Appendix Table A.1, second row).
} 
Table 2

Relationships between child test score $(y)$, child birth weight $\left(w_{g}\right)$ and maternal birth weight $\left(w_{g-1}\right)$.

\begin{tabular}{|c|c|c|c|c|}
\hline & Method & Relationship & Point-estimate $(\hat{\beta})$ & Conf. int. \\
\hline 1. & Regression: & testscore $=\alpha+\beta \log \left(b w_{g}\right)+u$ & $0.280^{* * *}$ & {$[0.258,0.303]$} \\
\hline 2. & Regression: & $\log \left(b w_{g}\right)=\alpha+\beta \log \left(b w_{g-1}\right)+u$ & $0.183^{* * *}$ & {$[0.177,0.189]$} \\
\hline 3. & Conjecture: & testscore $=\alpha+\beta \log \left(b w_{g-1}\right)+u$ & $0.051^{* * * *}$ & {$[0.047,0.056]$} \\
\hline 4. & Regression: & testscore $=\alpha+\beta \log \left(b w_{g-1}\right)+u$ & $0.245^{* * *}$ & {$[0.220,0.271]$} \\
\hline
\end{tabular}

Notes: The point estimate of the conjecture in row 3 is obtained by multiplying the point estimates from rows 1 and 2 . Point estimates, standard errors (SE) and confidence intervals are for the beta coefficient. The confidence interval indicates the point estimate \pm 1.96 times the standard error. Standard errors are clustered on the grandmother level. Standard errors for the conjecture are computed by means of bootstrapping with 500 replications. Test scores are standardized to have mean zero and unit standard deviation by test year, test subject and grade. Asterisks indicate significance at the following levels: ${ }^{*} p<0.1,{ }^{* *} p<0.05,{ }^{* * *} p<0.01$.

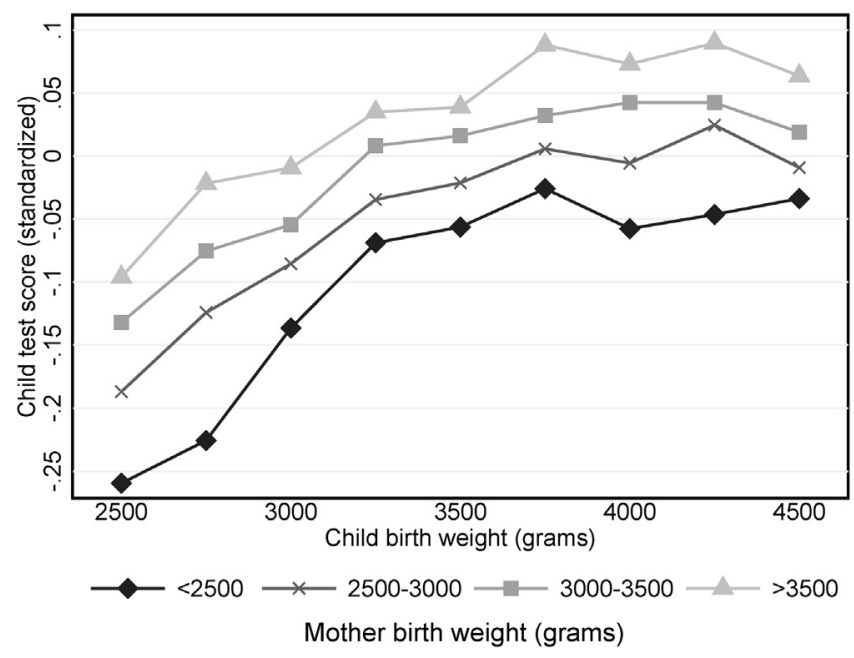

Fig. 2. Relationship between child test score, child birth weight, and maternal birth weight. Notes: Each dot shows the mean child test score for a child with the birth weight indicated on the $x$-axis (in 250-g bins) for four groups of maternal birth weights. Test scores are standardized to have mean zero and unit standard deviation by test year, test subject and grade.

By combining the above estimates of the association between birth weight and school test scores and the intergenerational association in birth weights, we may form a conjecture about the association between the test scores of the child and the birth weight of the mother. Intuitively, a one percent higher birth weight of the mother gives a 0.18 percentage increase in the birth weight of the child multiplied by a 0.30 higher test score per percentage increase in child birth weight. This gives approximately 0.05 SD percent higher child test scores, as reported in row 3 of Table 2. This conjecture would be correct if neonatal health of children is a 'sufficient statistic' incorporating maternal neonatal health. However, if we estimate a regression of child test scores on birth weight of the mother, we obtain a much stronger association with an estimated coefficient of 0.25 , as shown in row 4 of Table 2 . This estimate is five times as large as the conjecture. This difference is not a coincidence as shown by the high statistical precision of the coefficient in both the regression and the conjecture. The association between maternal birth weight and child test scores is more than 80 percent of the association between the child's own birth weight and test score. ${ }^{6}$

\footnotetext{
6 We obtain similar results (see Appendix Table A.1) if we estimate the regressions with birth weights in levels instead of employing a logarithmic transformation of birth weight as most commonly done.
}

Quantile regressions in Appendix Fig. A.1 show that the associations between birth weights and test scores are relatively homogenous across the test score distribution with maternal birth weight coefficients equal to 80-95 percent of the child birth weight coefficients.

Next, we explore the association between test scores and birth weight of the mother conditional on the birth weight of the child. Fig. 2 provides non-parametric evidence. The points in the graph show the mean child test score for 250 -g bins of child birth weight, divided into four sub-groups depending on the birth weight of the mother. As expected, the test score is steadily increasing in the birth weight of the child. More interestingly, the vertical distance between the graphs shows that child test scores are systematically higher at higher birth weights of the mother for each level of child birth weight. The figure reveals an almost parallel shift upwards in the relationship between test score and child birth weight when we move between the groups of maternal birth weights.

To quantify the importance of the mother's birth weight in a single number, we estimate the relative importance of maternal birth weight when both child birth weight and maternal birth weight are included in a regression. Column (1) in Table 3 displays the results from simple regressions of child test scores on the birth weights of the two generations. Panel A provides point estimates from estimating 
Table 3

Child test score regressed on child birth weight and maternal birth weight: controlling for parental resources.

\begin{tabular}{|c|c|c|c|}
\hline & (1) & $(2)$ & (3) \\
\hline \multicolumn{4}{|l|}{ A. Log-specification } \\
\hline Log mother birth weight & $\begin{array}{c}0.245^{* * *} \\
(0.013)\end{array}$ & $\begin{array}{c}0.200^{* * *} \\
(0.012)\end{array}$ & $\begin{array}{c}0.101^{* * *} \\
(0.012)\end{array}$ \\
\hline \multicolumn{4}{|l|}{ 2. Child birth weight } \\
\hline Log child birth weight & $\begin{array}{c}0.280^{* * * *} \\
(0.012)\end{array}$ & $\begin{array}{c}0.293^{* * *} \\
(0.012)\end{array}$ & $\begin{array}{c}0.206^{* * *} \\
(0.011)\end{array}$ \\
\hline \multicolumn{4}{|l|}{ 3. Child and mother birth weight } \\
\hline Log mother birthweight & $\begin{array}{c}0.200^{* * *} \\
(0.013)\end{array}$ & $\begin{array}{c}0.151^{* * *} \\
(0.013)\end{array}$ & $\begin{array}{c}0.066^{* * *} \\
(0.012)\end{array}$ \\
\hline Log child birthweight & $\begin{array}{c}0.250^{* * * *} \\
(0.012)\end{array}$ & $\begin{array}{c}0.266^{* * *} \\
(0.012)\end{array}$ & $\begin{array}{c}0.195^{* * *} \\
(0.011)\end{array}$ \\
\hline \multicolumn{4}{|l|}{ B. Indicator specification } \\
\hline Mother birth weight $<2500 \mathrm{~g}$ & $\begin{array}{c}-0.110^{* * *} \\
(0.010)\end{array}$ & $\begin{array}{c}-0.084^{* * *} \\
(0.009)\end{array}$ & $\begin{array}{c}-0.037^{* * *} \\
(0.008)\end{array}$ \\
\hline \multicolumn{4}{|l|}{ 2. Child birth weight } \\
\hline Child birth weight $<2500 \mathrm{~g}$ & $\begin{array}{c}-0.162^{* * *} \\
(0.010)\end{array}$ & $\begin{array}{c}-0.146^{* * *} \\
(0.010)\end{array}$ & $\begin{array}{c}-0.098^{* * *} \\
(0.009)\end{array}$ \\
\hline \multicolumn{4}{|l|}{ 3. Child and mother birth weight } \\
\hline Mother birth weight $<2500 \mathrm{~g}$ & $\begin{array}{c}-0.105^{* * *} \\
(0.010)\end{array}$ & $\begin{array}{c}-0.079 * * * \\
(0.009)\end{array}$ & $\begin{array}{c}-0.034^{* * *} \\
(0.008)\end{array}$ \\
\hline Child birth weight $<2500 \mathrm{~g}$ & $\begin{array}{c}-0.157^{* * *} \\
(0.010)\end{array}$ & $\begin{array}{c}-0.142^{* * *} \\
(0.010)\end{array}$ & $\begin{array}{c}-0.097^{* * *} \\
(0.009)\end{array}$ \\
\hline Clusters & 127,663 & 127,663 & 127,663 \\
\hline Observations & 895,587 & 895,587 & 895,587 \\
\hline Basic controls (119 controls) & & Yes & Yes \\
\hline Parental resources (219 controls) & & & Yes \\
\hline
\end{tabular}

Notes: The dependent variable is child test score standardized to have mean zero and unit standard deviation by test year, test subject and grade. Basic controls include: Child gender, mother and child sibsize (indicators), mother and child birth order (indicators), mother and child birth year (indicators), mother and child birth month (indicators), test year (indicators), test grade (indicators) and test subject (indicators). Parental resources include: parental education (indicators for the level), parental income percentile (indicators) and an indicator for self-employment. All parental controls are included separately for mother and father. All parent variables are measured in the calendar year, two years prior to child birth. Standard errors clustered on the grandmother level in parenthesis. Asterisks indicate significance at the following levels: ${ }^{*} p<0.1,{ }^{* *} p<0.05,{ }^{* * *} p<0.01$.

specifications where birth weight is included in logs. The coefficients in the third specification are somewhat smaller than the results from the univariate regressions in the first and second specifications, which is expected when birth weights are correlated across generations. ${ }^{7}$ More importantly, if we compare the mother coefficient to the child coefficient, then it is again 80 percent. Thus, the conclusion from the univariate regressions carry over to a multiple regression setting.

In panel $B$ of Table 3, we provide estimates from regressions where birth weight is included in terms of an indicator variable that equals one if an individual is born with low birth weight. In that case, the mother coefficient is around two-thirds of the child coefficient in both the univariate and multivariate regressions.

In column (2) of Table 3, we add basic covariates for child and mother characteristics. These covariates include child gender, child and mother birth order (indicators), number of siblings for both the child and the mother (indicators), child and mother birth year (indicators), child and mother birth month (indicators), test year (indicators), test subject (indicators), test grade (indicators) and child origin (indi-

\footnotetext{
7 When both child birth weight and maternal birth weight are important for the child test score, omitting one of these variables will naturally lead to a higher coefficient on the other variable, which will proxy for the omitted variable.
}

cator for non-western). In total, we estimate 119 additional parameters compared to the model in column (1). The point estimates on the birth weight of the child increase a little in the log specification, while the coefficients on maternal birth weight decrease a bit, but the mother coefficient is at least 50 percent of the child coefficient across all specifications (log and indicator, univariate and multivariate).

Column (3) of Table 3 reports the results from including an extensive set of controls for parental educational attainment and income. Education and income are traditionally used to assess intergenerational mobility, making it interesting to know whether parental neonatal health has predictive power on child development beyond what can be explained by education and income of parents. For each parent, we include eight indicators for the highest educational level completed two years prior to child birth, and we include 100 indicators for the percentile rank in the income distribution computed for the parents of the child birth cohort. Appendix Fig. A.2 shows that these measures are strongly correlated with the school performance of the child and also correlated with the birth weight of the mother. When going from the results in column (2) to column (3), which includes more than 300 explanatory variables, the birth weight coefficients fall considerably. However, the coefficient on maternal birth weight is still sizable and between one-third and one-half of the child coefficient across the different types of specifications. 
Table 4

Child test score regressed on child birth weight and maternal birth weight: within family variation in birth weight.

\begin{tabular}{|c|c|c|c|c|}
\hline & $(1)$ & $(2)$ & (3) & $(4)$ \\
\hline \multicolumn{5}{|l|}{ A. Log specification } \\
\hline Log mother birthweight & $\begin{array}{c}0.185^{* * *} \\
(0.030)\end{array}$ & $\begin{array}{c}0.096^{* * * *} \\
(0.028)\end{array}$ & $\begin{array}{l}0.127^{* * *} \\
(0.053)\end{array}$ & $\begin{array}{l}0.125^{* *} \\
(0.052)\end{array}$ \\
\hline \multicolumn{5}{|l|}{ 2. Child birth weight } \\
\hline Log child birthweight & $\begin{array}{c}0.288^{* * * *} \\
(0.030)\end{array}$ & $\begin{array}{c}0.205^{* * *} \\
(0.028)\end{array}$ & $\begin{array}{c}0.223^{* * *} \\
(0.036)\end{array}$ & $\begin{array}{c}0.201^{* * * *} \\
(0.035)\end{array}$ \\
\hline \multicolumn{5}{|l|}{ 3. Child and mother birth weight } \\
\hline Log mother birthweight & $\begin{array}{c}0.141^{* * * *} \\
(0.031)\end{array}$ & $\begin{array}{l}0.064^{* *} \\
(0.029)\end{array}$ & $\begin{array}{l}0.106^{* *} \\
(0.054)\end{array}$ & $\begin{array}{l}0.107^{* *} \\
(0.052)\end{array}$ \\
\hline Log child birthweight & $\begin{array}{l}0.261^{* * *} \\
(0.031)\end{array}$ & $\begin{array}{c}0.193^{* * * *} \\
(0.029)\end{array}$ & $\begin{array}{c}0.218^{* * * *} \\
(0.037)\end{array}$ & $\begin{array}{c}0.196^{* * * *} \\
(0.035)\end{array}$ \\
\hline \multicolumn{5}{|l|}{ B. Indicator specification } \\
\hline Mother birth weight $<2500 \mathrm{~g}$ & $\begin{array}{c}-0.102^{* * *} \\
(0.021)\end{array}$ & $\begin{array}{c}-0.067^{* * *} \\
(0.019)\end{array}$ & $\begin{array}{c}-0.076^{* *} \\
(0.033)\end{array}$ & $\begin{array}{c}-0.080^{* *} \\
(0.031)\end{array}$ \\
\hline \multicolumn{5}{|l|}{ 2. Child birth weight } \\
\hline Child birth weight $<2500 \mathrm{~g}$ & $\begin{array}{c}-0.115^{* * *} \\
(0.029)\end{array}$ & $\begin{array}{c}-0.063^{* *} \\
(0.028)\end{array}$ & $\begin{array}{c}-0.083^{* * *} \\
(0.032)\end{array}$ & $\begin{array}{c}-0.063^{* *} \\
(0.031)\end{array}$ \\
\hline \multicolumn{5}{|l|}{ 3. Child and mother birth weight } \\
\hline Mother birth weight $<2500 \mathrm{~g}$ & $\begin{array}{c}-0.098^{* * * *} \\
(0.021)\end{array}$ & $\begin{array}{c}-0.065^{* * *} \\
(0.019)\end{array}$ & $\begin{array}{c}-0.075^{* *} \\
(0.033)\end{array}$ & $\begin{array}{c}-0.080^{* *} \\
(0.031)\end{array}$ \\
\hline Child birth weight $<2500 \mathrm{~g}$ & $\begin{array}{c}-0.107^{* * *} \\
(0.029)\end{array}$ & $\begin{array}{c}-0.058^{* *} \\
(0.028)\end{array}$ & $\begin{array}{c}-0.082^{* * *} \\
(0.031)\end{array}$ & $\begin{array}{c}-0.062^{* *} \\
(0.031)\end{array}$ \\
\hline Clusters & 10,997 & 10,997 & 10,997 & 10,997 \\
\hline Observations & 101,199 & 101,199 & 101,199 & 101,199 \\
\hline Basic controls (119 controls) & Yes & Yes & Yes & Yes \\
\hline Parental resources (219 controls) & & Yes & & Yes \\
\hline Mother sibling FE (10,997 grandmothers) & & & Yes & Yes \\
\hline
\end{tabular}

Notes: Based on all cousins in the sample, who took the same test (same subject and grade, but not necessarily in the same year). The dependent variable is child test score standardized to have mean zero and unit standard deviation by test year, test subject and grade. Basic controls include: Child gender, mother and child sibsize (indicators), mother and child birth order (indicators), mother and child birth year (indicators), mother and child birth month (indicator), test year (indicators), test grade (indicators) and test subject (indicators). Parental resources include: parental education (indicators for the level), parental income percentile (indicators) and an indicator for self-employment. All parental controls are included separately for mother and father. All parental variables are measured in the calendar year, two years prior to child birth. Standard errors clustered on the grandmother level in parenthesis. Asterisks indicate significance at the following levels: ${ }^{*} p<0.1,{ }^{* *} p<0.05,{ }^{* * *} p<0.01$.

The additional parental variables are measured prior to child birth to avoid endogeneity. At this relatively early stage of the parents' careers, measures of human and economic capital may not be good at capturing the relevant levels of parental resources (Haider and Solon, 2006). In Appendix Table A.2, we replicate column (3) of Table 3 and show that we obtain very similar results when we measure parental income five years after child birth. We also show that the results are very similar if we weigh observations so that each family has the same weight in the regressions instead of each child having the same weight and if we use an alternative standardization of test scores. Finally, the table includes regression results for each of the six test subjects separately, which reveals only little variation in the birth weight coefficients across the different subjects.

\subsection{Within family variation in maternal neonatal health}

A key question is whether the association between maternal birth weight and child test scores reflects a causal relationship or a selection effect stemming from differences in family background of mothers. To isolate the effect of variation within families in neonatal health on child school performance, we follow previous literature by studying siblings. In our case, this corresponds to relating differences in birth weight of sisters to differences in test scores of their children. For this analysis, we consider the subsample of children where we observe at least two children with different mothers, but the same grandmother. This reduces the sample by a factor ten. Statistical significance is still evaluated based on standard errors clustered at the grandmother level.

Table 4 shows the results from this analysis. First, we redo the two last regressions reported in Table 3 for this subsample of children. By comparing columns (1) and (2) of Table 4 to columns (2) and (3) of Table 3, we see that the birth weight coefficients in general are a bit smaller, but very close to the coefficients in the full sample. In columns (3) and (4) of Table 4, we add fixed effects to the specifications in columns (1) and (2), thereby isolating the effect of differences in maternal birth weight between sisters on the test scores of their children. The point estimates on birth weights of both the child and the mother decrease somewhat when comparing column (3) to column (1). As might be expected, this shows that some of the original relationship between birth weight and school performance reflects differences in family background of the mothers. More importantly, the birth weights of both the child and the mother are still strongly significant and quantitatively important after including grandmother fixed effects. In col- 
umn (4) of Table 4, we further add the full set of controls for parental education and income. This has almost no impact on the point estimates and increases precision slightly. ${ }^{8}$ Across all log specifications with sibling fixed effects, we find that the coefficient on maternal birth weight is in the range 0.1-0.15 SD percent and approximately half of the coefficient on the child's own birth weight. ${ }^{9}$

Using siblings to isolate within family variation is done both in the literature studying the role of neonatal health and in the intergenerational literature (e.g. Currie and Moretti, 2007; Figlio et al., 2014; Bingley and Cappellari, 2017). Results based on siblings may be subject to siblingspecific unobserved factors. This is not the case for results based on twins (e.g. Figlio et al., 2014), but they may be subject to other concerns, as discussed by Almond and Mazumder (2013). Unfortunately, we have only a few twin mothers with children of school age. We report results with twin fixed effects in Appendix Table A.4, which shows larger point estimates for maternal birth weight in the twin sample than in the sibling sample. However, the twin sample is too small to obtain significant coefficients.

\subsection{Mechanisms behind the association between maternal birth weight and child school performance?}

The existing literature has established a causal relationship from birth weight to school performance, using variation within siblings and twins, but it is notoriously difficult to identify the mechanisms underlying this relationship. It is equally difficult to identify the mechanisms underlying the relationship between maternal birth weight and child school test scores. One possible explanation for the strong relationship between maternal birth weight and child test score is that maternal birth weight is associated with characteristics of the mother, which are important for child school performance and are not captured by the control set in the regressions. An example could be behavioral characteristics such as time investments of the mother during early childhood. However, this can only be an explanation if the variation in investment behavior of the mothers is not captured by our controls for variations in the children's own birth endowment, in family backgrounds of the mothers and in educational and economic resources of the parents.

Below we demonstrate an alternative and more subtle possible explanation for the strong relationship. Maternal birth weight may become significant in the regressions

\footnotetext{
8 Note that the coefficient on maternal birth weight increases somewhat when adding fixed effects to the specification including the full set of controls, i.e. from column (2) to column (4). This increase in the birth weight coefficient from including family fixed effects, although not significant, is similar to findings in Figlio et al. (2014).

9 Relatedly, we may ask whether the conclusion from the results in Table 2 still applies if grandmother fixed effects are included in the regressions. Appendix Table A.3 reports the results with fixed effects. As expected, the point estimates fall when removing the family background of mothers. More importantly, the main conclusion from Table 2 is unchanged. It is still the case that the association between maternal birth weight and child test scores (row 4 ) is roughly 5 times as high as the conjectured association (row 3 ). Thus, also in this case, child birth weight is not a sufficient statistic that incorporates maternal neonatal health.
}

although it only affects child test scores through an effect on child birth weight. This may occur if variation in child birth weight related to maternal birth weight is more important for child cognitive development than the variation in child birth weight unrelated to maternal birth weight. To see this formally, consider the following two relationships:

$w_{g}=\gamma_{w} w_{g-1}+\gamma_{\varepsilon} \varepsilon$,

$y_{g}=\alpha_{w} w_{g-1}+\alpha_{\varepsilon} \varepsilon+\sigma$,

where $y_{g}$ is the test score result of an individual in generation $g$ having birth weight $w_{g}$ and with maternal birth weight $w_{g-1}$, and where $\gamma_{w}, \gamma_{\varepsilon}, \alpha_{w}$ and $\alpha_{\varepsilon}$ are parameters, while $\varepsilon$ and $\sigma$ are stochastic terms. ${ }^{10}$ The first equation is a simple linear projection of child birth weight on parental birth weight, which provides a definitoric decomposition of the variation in child birth weight into variation related to parental birth weight (first term) and variation orthogonal to parental birth weight (second term). The second equation states that variation in child test scores is associated with variation in child birth weight-but allowing for separate effects of the two underlying components of child birth weight-as well as variation unrelated to child birth weight $(\sigma)$.

Theoretically, we may now distinguish between a relationship between test scores and variation in birth weight related and unrelated, respectively, to maternal birth weight according to

$$
\begin{aligned}
& \left.\frac{\partial y}{\partial w_{g}}\right|_{\partial w_{g-1}} \equiv \frac{\partial y / \partial w_{g-1}}{\partial w_{g} / \partial w_{g-1}}=\frac{\alpha_{w}}{\gamma_{w}},\left.\frac{\partial y}{\partial w_{g}}\right|_{\partial \varepsilon} \\
& \equiv \frac{\partial y / \partial \varepsilon}{\partial w_{g} / \partial \varepsilon}=\frac{\alpha_{\varepsilon}}{\gamma_{\varepsilon}} .
\end{aligned}
$$

If the sources of variation in child birth weight are equally important, $\alpha_{w} / \alpha_{\varepsilon}=\gamma_{w} / \gamma_{\varepsilon}$, then we would not need to make any decomposition as one extra gram of birth weight would lead to the same change in test score independent of the underlying source. On the other hand, if $\alpha_{w} / \alpha_{\varepsilon}>$ $\gamma_{w} / \gamma_{\varepsilon}$ then variation in birth weight related to parental birth weight is more strongly related to child test scores than variation unrelated to parental birth weight and vice versa.

An OLS regression of child test score on child birth weight alone gives

$$
\begin{gathered}
\hat{\beta}_{\mathrm{OLS}}=\frac{\operatorname{cov}\left(y, w_{g}\right)}{\operatorname{var}\left(w_{g}\right)}=\Omega \frac{\boldsymbol{\alpha}_{\boldsymbol{w}}}{\gamma_{\boldsymbol{w}}}+(1-\Omega) \frac{\alpha_{\varepsilon}}{\gamma_{\varepsilon}}, \\
\text { where } \Omega \equiv \frac{\gamma_{w}^{2} \operatorname{var}\left(w_{g-1}\right)}{\gamma_{w}^{2} \operatorname{var}\left(w_{g-1}\right)+\gamma_{\varepsilon}^{2} \operatorname{var}(\varepsilon)},
\end{gathered}
$$

showing that the estimate is a weighted average of the two underlying sources of variation. Adding parental birth weight to the regression increases the explanatory power if the underlying source of variation in child birth weight

\footnotetext{
10 It is possible to normalize $\gamma_{\varepsilon}$ to one, but we have chosen this symmetric specification of the relationships because it is helpful for the interpretation of the result below. Note also that the equations may represent transformed variables, e.g. the logarithmic values of birth weights.
} 


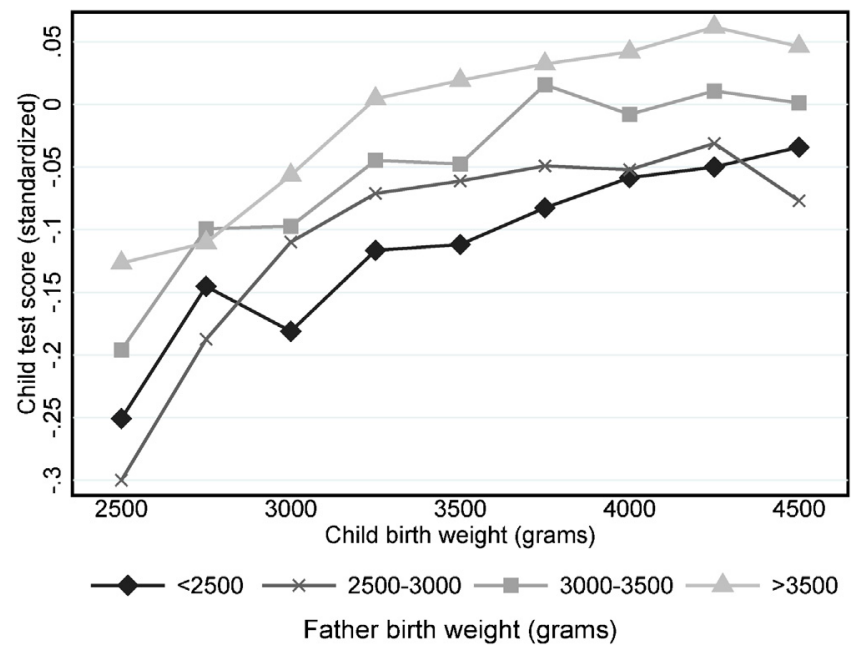

Fig. 3. Relationship between child test score, child birth weight and birth weight of the father. Notes: Each dot shows the mean child test score for a child with the birth weight indicated on the $x$-axis (in 250-g bins) for four birth weight groups of fathers. Test scores are standardized to have mean zero and unit standard deviation by test year, test subject and grade.

matters, $\alpha_{w} / \alpha_{\varepsilon} \neq \gamma_{w} / \gamma_{\varepsilon}$. This is seen by isolating $w_{g-1}$ in Eq. (1) and substituting the result into (2), which gives

$y=\underbrace{\frac{\alpha_{\varepsilon}}{\gamma_{\varepsilon}}}_{\beta_{0}} w_{g}+\underbrace{\gamma_{w}\left(\frac{\alpha_{w}}{\gamma_{w}}-\frac{\alpha_{\varepsilon}}{\gamma_{\varepsilon}}\right)}_{\beta_{1}} w_{g-1}+\sigma$.

This equation shows that, in a multivariate regression including both birth weights, a positive coefficient on parental birth weight $\left(\beta_{1}>0\right)$ may reflect that the family component in the birth weight of the child is more important than the component unrelated to parental birth weight, i.e. $\alpha_{w} / \gamma_{w}>\alpha_{\varepsilon} / \gamma_{\varepsilon}{ }^{11}$ This result demonstrates that it is possible that parental birth weight becomes significant in the regression even though its impact on child cognitive development entirely runs through its effect on child birth weight.

We cannot distinguish empirically between the two suggested explanations underlying the strong association between maternal birth weight and child school performance, but common for both explanations is that birth endowments play an important role for cognitive development of the next generation.

\subsection{Including birth weight information of the father}

So far, the empirical analysis has only looked at the relationship between maternal birth weight and child school performance. Our data allows us to include information about the neonatal health of the (biological) fathers. This requires, however, that we restrict the sample to all children with fathers born in 1973 or later in order to have the necessary birth weight information. This reduces the

\footnotetext{
11 In principle, it would be possible to measure the relative importance of the two underlying sources of variation in child birth weight $\left(\alpha_{w} / \gamma_{w}\right.$ vs. $\alpha_{\varepsilon} / \gamma_{\varepsilon}$ ) in predicting test scores, but identification would require that we excluded the first type of explanation behind the association between maternal birth weight and child test scores.
}

number of observations to less than a half and implies that fathers in the sample are younger than in the full sample. Fig. 3 mimics Fig. 2, but is based on the birth weight of the father instead of the mother. The lines are slightly more volatile, likely due to the smaller sample, but the overall picture is very similar. Having a father with a higher birth weight shifts the whole relationship between child test scores and child birth weight upwards.

Table 5 shows estimates from regressing child test scores on the birth weight of the child and birth weights of both parents. Columns (1) and (2), specifications A1 and B1 show the results for the univariate regressions of child test scores on mother and father birth weight, respectively. The point estimates on the birth weights of the two parents are remarkably similar in magnitude, also when we include the child's own birth weight in specifications A2 and B2. In column (3), we include the birth weights of both parents in the regressions. The point estimates are again very similar, and they are also similar in size to the specifications where they are included separately. Finally, in column (4), we add the full set of controls. In this specification, we also control for father birth year (indicators), birth month (indicators), birth order (indicators) and siblings (indicators). As in the previous specifications, the point estimates on the parental birth weights decrease considerably, but each of them is still more than one-fourth of the child coefficient. Again, the birth weights of the two parents are close to equally important in predicting child test scores.

\section{Robustness}

In addition to the standard specification with the logarithmic transformation of birth weight, we have shown all main regression results with a low birth weight indicator. In this section, we provide two additional tests of the generalizability of our findings. First, we address the issue that our sample is limited to relatively young mothers, because information on birth weight is only available from 1973. Second, as an external validity exercise, we replicate recent 
Table 5

Child test score regressed on child birth weight, maternal birth weight and paternal birth weight.

\begin{tabular}{|c|c|c|c|c|}
\hline & (1) & (2) & (3) & (4) \\
\hline \multicolumn{5}{|l|}{ A. Log specification } \\
\hline Log mother birth weight & $\begin{array}{l}0.235^{* * *} \\
(0.017)\end{array}$ & & $\begin{array}{c}0.229 * * * \\
(0.017)\end{array}$ & $\begin{array}{l}0.091^{* * *} \\
(0.015)\end{array}$ \\
\hline Log father birth weight & & $\begin{array}{l}0.241^{* * *} \\
(0.018)\end{array}$ & $\begin{array}{l}0.235^{* * *} \\
(0.018)\end{array}$ & $\begin{array}{l}0.091^{* * *} \\
(0.016)\end{array}$ \\
\hline \multicolumn{5}{|l|}{ 2. With child birth weight } \\
\hline Log mother birth weight & $\begin{array}{l}0.188^{* * *} \\
(0.018)\end{array}$ & & $\begin{array}{l}0.186^{* * *} \\
(0.017)\end{array}$ & $\begin{array}{l}0.057^{* * *} \\
(0.015)\end{array}$ \\
\hline Log father birth weight & & $\begin{array}{l}0.214^{* * *} \\
(0.018)\end{array}$ & $\begin{array}{l}0.212^{* * *} \\
(0.018)\end{array}$ & $\begin{array}{l}0.074^{* * *} \\
(0.016)\end{array}$ \\
\hline Log child birth weight & $\begin{array}{c}0.250^{* * *} \\
(0.016)\end{array}$ & $\begin{array}{l}0.261^{* * *} \\
(0.015)\end{array}$ & $\begin{array}{l}0.233^{* * *} \\
(0.016)\end{array}$ & $\begin{array}{l}0.186^{* * *} \\
(0.015)\end{array}$ \\
\hline \multicolumn{5}{|l|}{$\begin{array}{l}\text { B. Indicator specification } \\
\text { 1. Without child birth weight }\end{array}$} \\
\hline Mother birth weight $<2500 \mathrm{~g}$ & $\begin{array}{c}-0.103^{* * *} \\
(0.013)\end{array}$ & & $\begin{array}{c}-0.102^{* * *} \\
(0.013)\end{array}$ & $\begin{array}{c}-0.034^{* * * *} \\
(0.011)\end{array}$ \\
\hline Father birth weight $<2500 \mathrm{~g}$ & & $\begin{array}{c}-0.091^{* * *} \\
(0.014)\end{array}$ & $\begin{array}{c}-0.091^{* * *} \\
(0.014)\end{array}$ & $\begin{array}{c}-0.025^{* *} \\
(0.013)\end{array}$ \\
\hline \multicolumn{5}{|l|}{ 2. With child birth weight } \\
\hline Mother birth weight $<2500 \mathrm{~g}$ & $\begin{array}{c}-0.097^{* * *} \\
(0.012)\end{array}$ & & $\begin{array}{c}-0.097^{* * *} \\
(0.012)\end{array}$ & $\begin{array}{r}-0.031^{* * *} \\
(0.011)\end{array}$ \\
\hline Father birth weight $<2500 \mathrm{~g}$ & & $\begin{array}{c}-0.090^{* * *} \\
(0.014)\end{array}$ & $\begin{array}{c}-0.089^{* * *} \\
(0.014)\end{array}$ & $\begin{array}{c}-0.025^{*} \\
(0.013)\end{array}$ \\
\hline Child birth weight $<2500 \mathrm{~g}$ & $\begin{array}{c}-0.153^{* * *} \\
(0.013)\end{array}$ & $\begin{array}{c}-0.157^{* * *} \\
(0.013)\end{array}$ & $\begin{array}{c}-0.152^{* * *} \\
(0.013)\end{array}$ & $\begin{array}{c}-0.086^{* * * *} \\
(0.013)\end{array}$ \\
\hline Clusters & 82,818 & 82,818 & 82,818 & 82,818 \\
\hline Observations & 470,601 & 470,601 & 470,601 & 470,601 \\
\hline Basic controls (119 controls) & & & & Yes \\
\hline Parental resources ( 281 controls) & & & & Yes \\
\hline
\end{tabular}

Notes: Based on the subsample where information about paternal birth weight exists (all fathers born in 1973 or later). The dependent variable is child test score standardized to have mean zero and unit standard deviation by test year, test subject and grade. Basic controls include: Child gender, father, mother and child sibsize (indicators), father, mother and child birth order (indicators), father, mother and child birth year (indicators), father, mother and child birth month (indicators), test year (indicators), test grade (indicators) and test subject (indicators). Parental resources include: parental education (indicators for the level), parental income percentile (indicators) and an indicator for self-employment. All parental controls are included separately for mother and father. All parent variables are measured in the calendar year, two years prior to child birth. Standard errors clustered on the grandmother level in parenthesis. Asterisks indicate significance at the following levels: ${ }^{*} p<0.1,{ }^{* *} p<0.05,{ }^{* * *} p<0.01$.

results for the US on the relationship between child test scores and child birth weight.

\subsection{Replication of results with more representative survey data}

To assess whether the estimated relationships are affected by the fact that we only observe birth weight for mothers born after 1973, we replicate results from Section 3.1 on survey data from the Danish National Birth Cohort (DNBC). The DNBC is a nationwide cohort study based on a sample of women who were pregnant between 1997 and 2004. The survey contains self-reported information about the mothers' own birth weight. While the self-reported birth weights likely contain some measurement errors, they provide us with birth weights for a sample of 39,128 mothers, with an age distribution that is more similar to the overall population than the sample based on the birth registry (see Fig. 4).

In Table 6, we show regression results for the relationship between child test scores and maternal birth weight using the survey sample. The results are comparable to Table 3. In general, the coefficients are somewhat lower in the survey sample, although the differences are not so large when we include all the covariates in column (3). For example, the coefficient on maternal birth weight is 0.086 in the first specification, which should be compared to 0.101 in Table 3. More importantly, if we compare the relative size of the coefficient on the birth weight of the mother to the birth weight of the child, then it is reasonably stable across the two samples, in particular in the log specification. For example, in the univariate regressions the mother coefficient is about 90 percent of the child coefficient in both samples, in the multivariate regressions without additional controls it is about 80 percent in both cases, and when including the full set of controls it is about 30 percent in both cases. This suggests that the sample restriction that mothers are born in 1973 or later is not crucial for the findings in the main analysis.

\subsection{Replicating recent US results on the relationship between child birth weight and test score}

In this subsection we replicate recent US evidence by Figlio et al. (2014) on the relationship between variation in birth weight of children and their test score results early in school. Their sample consists of all children born in Florida between 1992 and 2002. Following their study, we consider 


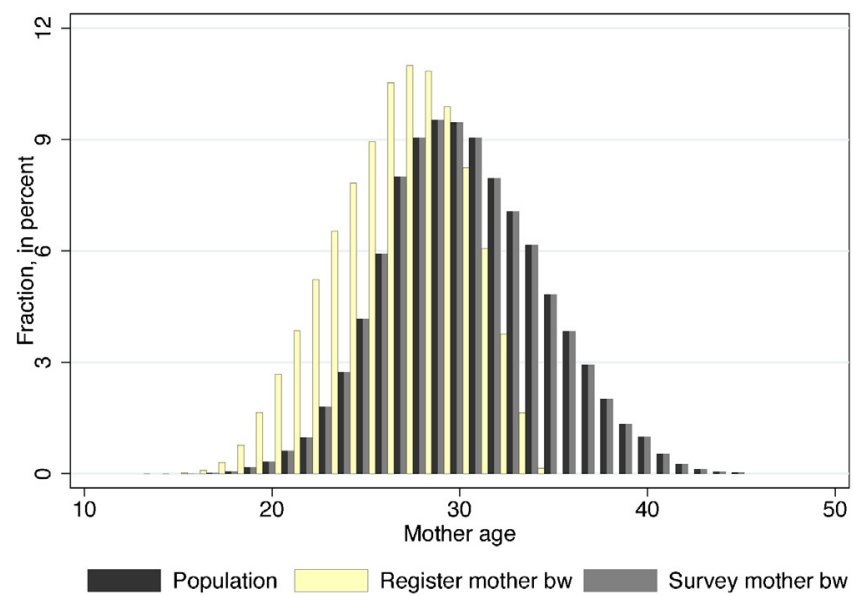

Fig. 4. Mother age distribution by sample. Notes: The histograms show the distribution of mothers' age at child birth for the overall population (black bars) of children born in the period 1995-2007, for the children that are matched to mother birth weight from the birth registry (yellow bars) and for children with survey birth weight information on mothers' birth weight (grey bars).

Table 6

Regression of child test score on mother birth weight based on DNBC survey data.

\begin{tabular}{|c|c|c|c|}
\hline & (1) & (2) & (3) \\
\hline \multicolumn{4}{|l|}{ A. Log-specification } \\
\hline Log mother birth weight & $\begin{array}{c}0.200^{* * *} \\
(0.022)\end{array}$ & $\begin{array}{c}0.174^{* * * *} \\
(0.021)\end{array}$ & $\begin{array}{c}0.086^{* * *} \\
(0.019)\end{array}$ \\
\hline \multicolumn{4}{|l|}{ 2. Child birth weight } \\
\hline Log child birth weight & $\begin{array}{c}0.222^{* * *} \\
(0.022)\end{array}$ & $\begin{array}{c}0.280^{* * * *} \\
(0.023)\end{array}$ & $\begin{array}{c}0.187^{* * *} \\
(0.021)\end{array}$ \\
\hline \multicolumn{4}{|c|}{ 3. Both child and mother birth weight } \\
\hline Log mother birth weight & $\begin{array}{c}0.166^{* * *} \\
(0.022)\end{array}$ & $\begin{array}{c}0.130^{* * * *} \\
(0.022)\end{array}$ & $\begin{array}{c}0.055^{* * * *} \\
(0.020)\end{array}$ \\
\hline Log child birth weight & $\begin{array}{c}0.191^{* * *} \\
(0.022)\end{array}$ & $\begin{array}{c}0.252^{* * *} \\
(0.023)\end{array}$ & $\begin{array}{c}0.175^{* * *} \\
(0.021)\end{array}$ \\
\hline \multicolumn{4}{|l|}{ B. Indicator specification } \\
\hline Mother birth weight $<2500 \mathrm{~g}$ & $\begin{array}{c}-0.121^{* * *} \\
(0.017)\end{array}$ & $\begin{array}{c}-0.104^{* * *} \\
(0.017)\end{array}$ & $\begin{array}{c}-0.039^{* *} \\
(0.015)\end{array}$ \\
\hline \multicolumn{4}{|l|}{ 2. Child birth weight } \\
\hline Child birth weight $<2500 \mathrm{~g}$ & $\begin{array}{c}-0.142^{* * *} \\
(0.021)\end{array}$ & $\begin{array}{c}-0.136^{* * *} \\
(0.021)\end{array}$ & $\begin{array}{c}-0.075^{* * *} \\
(0.019)\end{array}$ \\
\hline \multicolumn{4}{|c|}{ 3. Both child and mother birth weight } \\
\hline Mother birth weight $<2500 \mathrm{~g}$ & $\begin{array}{c}-0.119^{* * *} \\
(0.017)\end{array}$ & $\begin{array}{c}-0.102^{* * *} \\
(0.017)\end{array}$ & $\begin{array}{c}-0.038^{* *} \\
(0.015)\end{array}$ \\
\hline Child birth weight $<2500 \mathrm{~g}$ & $\begin{array}{c}-0.136^{* * * *} \\
(0.021)\end{array}$ & $\begin{array}{c}-0.131^{* * *} \\
(0.021)\end{array}$ & $\begin{array}{c}-0.073^{* * *} \\
(0.019)\end{array}$ \\
\hline Clusters & 30,510 & 30,510 & 30,510 \\
\hline Observations & 368,372 & 368,372 & 368,372 \\
\hline Basic controls (119 controls) & & Yes & Yes \\
\hline Parental resources (219 controls) & & & Yes \\
\hline
\end{tabular}

Notes: The dependent variable is child test score standardized to have mean zero and unit standard deviation by test year, test subject and grade. Basic controls include: Child gender, mother and child sibsize (indicators), mother and child birth order (indicators), mother and child birth year (indicators), mother and child birth month (indicators), test year (indicators), test grade (indicators) and test subject (indicators). Parental resources include: parental education (indicators for the level), parental income percentile (indicators) and an indicator for self-employment. All parental controls are included separately for mother and father. All parent variables are measured in the calendar year, two years prior to the child birth. Standard errors clustered on the grandmother level in parenthesis. Asterisks indicate significance at the following levels: ${ }^{*} p<0.1 .{ }^{* *} p<0.05,{ }^{* * *} p<0.05$.

variation in the birth weights of singletons as well as fixed effect models based on siblings and twins. To resemble their analysis as closely as possible, we restrict the sample to test score results for only math and reading. Appendix A.7 provides non-parametric results on the relationship between test score and birth weight, while Table 7 reports the results from estimating a linear relationship between test score and log birth weight, individually, for singletons, siblings and twins.

Columns (1) and (2) of Table 7 report results from OLS regressions where column (2) includes similar control variables as in Figlio et al. (2014). The coefficient for singletons in column (1) is, as expected, close to the coefficient in the first row of Table 2. Figlio et al. (2014) do not report results 
Table 7

Child test score regressed on child birth weight.

\begin{tabular}{lccc}
\hline & $(1)$ & $(2)$ & $(3)$ \\
\hline A. Singletons & & & \\
Log child birth weight & $\begin{array}{c}0.324^{* * *} \\
(0.013)\end{array}$ & $\begin{array}{c}0.306^{* * *} \\
(0.012)\end{array}$ & \\
& 662,969 & 662,969 & \\
Observations & & & \\
B. Siblings ( singletons only) & & & \\
Log child birth weight & $0.319^{* * *}$ & $0.304^{* * *}$ & $0.205^{* * *}$ \\
& $(0.015)$ & $(0.014)$ & $(0.019)$ \\
Observations & 488,358 & 488,358 & 488,358 \\
C. Twins & & & \\
Log child birth weight & $0.145^{* * *}$ & $0.212^{* * *}$ & $0.454^{* * *}$ \\
& $(0.049)$ & $(0.046)$ & $(0.089)$ \\
Observations & 20,997 & 20,997 & 20,997 \\
Controls (55 controls) & & Yes & Yes \\
Sibling/twin FE & & & Yes \\
\hline
\end{tabular}

Notes: The sample is based on all children born between 1995 and 2007 and matched to test scores, child birth weight, mother birth weight, as well as parental birth date and birth order. Only tests in math and reading are included. This table splits the children into singletons (panel A), siblings (panel B) and twins (panel C). The dependent variable is child test score standardized to have mean zero and unit standard deviation by test year, test subject and grade. Controls included are child birth month and year (indicators), child birth order and number of siblings (indicators), maternal age at child birth (indicators), maternal education (indicators), maternal origin and maternal marital status. Standard errors clustered on the mother level in parenthesis. Asterisks indicate significance at the following levels: ${ }^{*} p<0.1,{ }^{* *} p<0.05,{ }^{* * *} p<0.01$.

without controls, but when we include controls we obtain a coefficient of 0.306 for singletons, which should be compared to a coefficient of 0.285 reported in their Table 2 . The corresponding coefficient for siblings is 0.304 in our case, which is not far from the 0.277 in their Table 2 . The twin coefficient is 0.212 , which is somewhat lower than their estimate of 0.285 . In line with their study, we find that the sibling coefficient falls while the twin coefficient increases when including twin/sibling fixed effects. The sibling coefficient becomes a little lower in our case ( 0.205 vs. 0.238$)$, while the twin coefficient becomes nearly identical across the two countries ( 0.454 vs. 0.443 ).

Appendix A.7 provides non-parametric evidence on the relationship between birth weight and test scores for twins. These results are also very similar to the findings in Figlio et al. (2014). For example, we find that the heavier twin performs significantly better on average in school tests, and the difference is reasonably stable across school grades at a level of about five percent of a standard deviation to the lighter twin, as in Figlio et al. (2014).

The very similar findings for Denmark and Florida suggest that our main results on the relationship between neonatal health of parents and cognitive development of children may also be relevant for the US, and probably for other countries. It is also interesting that the relationship between neonatal health and test scores within a population is so similar across two countries with such different institutional settings.

\section{Concluding remarks}

Our results show that the birth weight of children is not a sufficient statistic incorporating relevant information about parental neonatal health when predicting key child outcomes. Inequality in birth endowments of parents is a strong predictor of the cognitive development of their children, conditional on the children's own birth endowments, and this also applies when looking at within-family variation and controlling for a large set of variables capturing parental economic resources. These intergenerational findings suggest that neonatal health is even more important than suggested by existing evidence documenting a relationship between differences across individuals in neonatal health and differences in later outcomes of the same individuals. Many recent studies have found evidence of causal effects on birth endowments from a number of external factors, such as nutritional shocks, health shocks, stress, tobacco policy and environmental factors (e.g. Almond and Mazumder, 2011; Currie and Schwandt, 2013, 2016; Harris et al., 2015; Carlson, 2015; Black et al., 2016; Persson and Rossin-Slater, 2018). ${ }^{12}$ Our findings indicate that such external factors can have important effects persisting into the next generation.

Our analysis of the relationship between parental endowments and child outcomes is limited by data availability. At some point in the future, with additional information from new cohorts, it will be possible to strengthen our results in different ways. For example, we do not have a large enough sample to examine within-twin variation in the birth weight of mothers or to look at within family variation in paternal birth endowments. Data for additional cohorts will, at some point, make this possible. In addition, data for additional cohorts will make it possible to study a more representative sample of the population, although the survey data findings in Section 4.1 indicate that the main results will be unchanged.

The well-known empirical relationship between child birth weight and child test score begs the question: what are the underlying mechanisms generating this association? Similarly, our empirical findings beg the question: why do birth weights of parents predict child cognitive development even when controlling for the child's own birth endowment, family background of mothers (i.e. mother sibling fixed effects) and educational and economic resources of the parents? As described in Section 3.3, one potential explanation is that parental birth endowments are associated with other characteristics of the mothers that are important for child school performances and not fully captured by the controls. Another potential explanation is that the family component in child birth weight is more strongly related to child cognitive development than the variation in child birth weight unrelated to family background. It is difficult to distinguish empirically between these two explanations. An example of the first type of explanation is that mothers who are heavier at birth not only get heavier children themselves, but also invest more in their children in early childhood without this being fully captured by the observable background characteristics of the parents. Such an explanation would relate to

\footnotetext{
12 Another strand of literature explores the role of genes for the relationship between birth weight and later life outcomes (e.g. Cook and Fletcher, 2015).
} 
recent studies surveyed in Almond et al. (2018) examining the importance of parental investment in early childhood. Unfortunately, our data does not allow us to test hypotheses along this line, which we leave for future research.

\section{Appendix A. Supplementary data}

Supplementary data associated with this article can be found, in the online version, at https://doi.org/10.1016/ j.jhealeco.2019.102247.

\section{References}

Almond, D., Currie, J., 2010. Human capital development before age five. In: Card, David, Ashenfelter, Orley (Eds.), Handbook of Labor Economics, vol. 4b. Elsevier, pp. 1315-1486.

Almond, D., Currie, J., 2011. Killing me softly: the fetal origins hypothesis. J. Econ. Perspect. 25 (3), 153-172.

Almond, D., Currie, J., Duque, V., 2018. Childhood circumstances and adult outcomes: act ii. J. Econ. Lit. 56 (4), 1360-1446.

Almond, D., Mazumder, B., 2011. Health capital and the prenatal environment: the effect of Ramadan observance during pregnancy. Am. Econ. J. Appl. Econ.

Almond, D., Mazumder, B., 2013. Fetal origins and parental responses. Annu. Rev. Econ. 5, 37-56.

Andersen, S.C., Humlum, M.K., Nandrup, A.B., 2016. Increasing instruction time in school does increase learning. Proc. Natl. Acad. Sci. U.S.A. 113 (27), 7481-7484.

Beuchert, L.V., Nandrup, A.B., 2018. The Danish national tests at a glance. Danish J. Econ. 2, 1-37.

Bharadwaj, P., Bietenbeck, J., Lundborg, P., Rooth, D.-O., 2019. Birth weight and vulnerability to a macroeconomic crisis. J. Health Econ. 66, 136-144.

Bharadwaj, P., Lundborg, P., Rooth, D.-O., 2018. Birth weight in the long run. J. Hum. Resour. 53 (1), 189-231.

Bingley, P., Cappellari, L., 2019. Correlations of brothers' earnings and intergenerational transmission. Rev. Econ. Stat. 101 (2), 370-383.

Black, S.E., Devereux, P.J., 2011. Recent Developments in Intergenerational Mobility, vol. 4. Handbook of Labor Economics Elsevier, pp. 1487-1541 (chap. 16).

Black, S.E., Devereux, P.J., Salvanes, K.G., 2007. From the cradle to the labor market? The effect of birth weight. Q. J. Econ. 122 (1), 409-439.

Black, S.E., Devereux, P.J., Salvanes, K.G., 2016. Does grief transfer across generations? Bereavements during pregnancy and child outcomes. Am. Econ. J. Appl. Econ. 8 (1), 193-223.
Boserup, S.H., Kopczuk, W., Kreiner, C.T., 2018. Born with a silver spoon: Danish evidence on intergenerational wealth formation from cradle to adulthood. Econ. J. 128, F514-F544.

Carlson, K., 2015. Fear itself: the effects of distressing economic news on birth outcomes. J. Health Econ. 41, 117-132.

Chaikind, S., Corman, H., 1991. The impact of low birthweight on special education costs. J. Health Econ. 10, 291-311.

Chetty, R., Grusky, D., Hell, M., Hendren, N., Manduca, R., Narang, J., 2017. The fading American dream: trends in absolute income mobility since 1940. Science 356 (6336), 398-406.

Cook, C.J., Fletcher, J.M., 2015. Understanding heterogeneity in the effects of birth weight on adult cognition and wages. J. Health Econ. 41, 107-116.

Currie, J., 2011. Inequality at birth: some causes and consequences. Am. Econ. Rev. 101 (3), 1-22, http://dx.doi.org/10.1257/aer.101.3.1.

Currie, J., Moretti, E., 2007. Biology as destiny? Short- and long-run determinants of intergenerational transmission of birth weight. J. Labor Econ. 25 (2), 231-264.

Currie, J., Schwandt, H., 2013. Within-mother analysis of seasonal patterns in health at birth. Proc. Natl. Acad. Sci. U. S. A. 110 (30), 12265-12270.

Currie, J., Schwandt, H., 2016. The 9/11 dust cloud and pregnancy outcomes: a reconsideration. J. Hum. Resour. 51 (4), 805-831.

Figlio, D., Guryan, J., Karbownik, K., Roth, J., 2014. The effects of poor neonatal health on children's cognitive development. Am. Econ. Rev. 104 (12), 3921-3955.

Haider, S., Solon, G., 2006. Life-cycle variation in the association between current and lifetime earnings. Am. Econ. Rev. 96 (4), 1308-1320.

Harris, J.E., Balsa, A.I., Triunfo, P., 2015. Tobacco control campaign in Uruguay: impact on smoking cessation during pregnancy and birth weight. J. Health Econ. 42, 186-196.

Kleven, H.J., Knudsen, M.B., Kreiner, C.T., Pedersen, S., Saez, Emmanuel, 2011. Unwilling or unable to cheat? Evidence from a tax audit experiment in Denmark. Econometrica 79 (3), 651-692.

Landersø, R., Heckman, J.J., 2017. The Scandinavian fantasy: the sources of intergenerational mobility in Denmark and the US. Scand. J. Econ. 119 (1), 178-230.

Persson, P., Rossin-Slater, M., 2018. Family ruptures, stress, and the mental health of the next generation. Am. Econ. Rev. 108, 1214-1252.

Royer, H., 2009. Separated at girth: US twin estimates of the effects of birth weight. Am. Econ. J. Appl. Econ. 1 (1), 49-85.

Sievertsen, H.H., Gino, F., Piovesan, M., 2016. Cognitive fatigue influences students' performance on standardized tests. Proc. Natl. Acad. Sci. U.S.A. 113 (10), 2621-2624.

Solon, G., 1999. Intergenerational mobility in the labor market, vol. 3: Part A Handbook of Labor Economics. Elsevier, pp. 1761-1800 (Chapter 29) 